\title{
Ulfin Rethnam
}

\section{Floating knee injuries: more than what meets the eye}

Received: 12 December 2005 / Accepted: 12 December 2005 / Published online: 4 April 2006

C) Springer-Verlag 2006

I read with interest the article "Floating knee injuries: long term results of four treatment methods". I agree with the authors that these injuries are difficult to manage, especially in developing countries, due to both financial and resource constraints. I would like to bring to light a few important aspects to this injury.

The classification proposed by Blake and McBryde (1975) [2] gives more information about the associated injuries in the affected limb (intracapsular/extracapsular

This comment refers to the article available at: http://dx.doi. org/10.1007/s00264-005-0679-x

\section{U. Rethnam}

Clinical Research Fellow Orthopaedics,

Department of Orthopaedics, Wrexham Maelor Hospital,

Wrexham, UK

U. Rethnam $(\bowtie)$

18 Bron Y Nant, Croesnewydd road,

Wrexham, LL13 7TX, UK

e-mail: ulfinr@yahoo.com

Tel.: +44-777-9095559 femoral neck fractures and ankle fractures) which could have implications on the type of surgical treatment. These patients have a high incidence of knee ligament injuries that need assessment after surgical stabilisation of both the fractures. [1, 3] Fat embolism is more common in these patients and they need to be monitored closely during the initial period. Intramedullary nailing for both the fractures (femur and tibia) is the best treatment option for early return of function in these patients.

\section{References}

1. Paul GR, Sawka MW, Whitelaw GP (1990) Fractures of the ipsilateral femur and tibia: emphasis on intra-articular and soft tissue injury. J Orthop Trauma 4(3):309-314

2. Blake R, McBryde A Jr (1975) The floating knee: ipsilateral fracture of the tibia and femur. South Med J 68(1):13-16

3. Szalay MJ, Hosking OR, Annear P (1990) Injury of knee ligament associated with ipsilateral femoral shaft fractures and with ipsilateral femoral and tibial shaft fractures. Injury 21 (6):398-400 